\title{
Factors influencing vibration sense thresholds used to assess occupational exposures to hand transmitted vibration
}

\author{
Noriaki Harada, Michael J Griffin
}

\section{Abstract}

The effects of various conditions, including temporary threshold shifts (TTS) induced by exposure to vibration on vibration sense thresholds, have been investigated. The vibration sense thresholds of five subjects were measured on the middle fingertip of the left hand. A contactor with a diameter of $7 \mathrm{~mm}$ was surrounded by three alternative plates with holes of different sizes. The contact force was controlled at either $1 \mathrm{~N}, 2 \mathrm{~N}$, or $3 \mathrm{~N}$. For the TTS test, the left hand was exposed to vibration at $20 \mathrm{~ms}^{-2}$ rms for five minutes. The frequencies of both the exposure to vibration and the vibration threshold test were in the range $16 \mathrm{~Hz}$ to $500 \mathrm{~Hz}$. Using a surround around the contactor greatly reduced the vibration sense threshold at $16 \mathrm{~Hz}$ and $31.5 \mathrm{~Hz}$ but increased the threshold at $125 \mathrm{~Hz}, 250 \mathrm{~Hz}$, and $500 \mathrm{~Hz}$. An effect of contact force was seen only at the higher frequencies; larger contact forces led to lower thresholds at $125 \mathrm{~Hz}, 250 \mathrm{~Hz}$, and $500 \mathrm{~Hz}$. As temperature of the finger skin decreased, the vibration thresholds increased, with the changes at higher frequencies greater than those at lower frequencies. The TTS at $16 \mathrm{~Hz}$ and $31.5 \mathrm{~Hz}$ measured 0.5 minutes after exposure to vibration $\left(\right.$ TTS $_{0.5}$ ) were highest after exposures to vibration at lower frequencies. The TTS $_{0.5}$ at $63 \mathrm{~Hz}$ was similar after exposure to all frequencies. The TTS $_{0.5}$ values at $125 \mathrm{~Hz}$, $250 \mathrm{~Hz}$, and $500 \mathrm{~Hz}$ were highest after exposures to vibration at $125 \mathrm{~Hz}$ and $250 \mathrm{~Hz}$. It was apparent that the physiological characteristics of vibration sensation at low and high frequencies differed significantly. These find-

Department of Public Health, Ehime University School of Medicine, Ehime, Japan. Present address: Department of Hygiene, Yamaguchi University School of Medicine, Ube, Japan

N Harada

Human Factors Research Unit, Institute of Sound and Vibration Research, Southampton University, England

M J Griffin ings suggest that two representative frequencies can be used when evaluating the neurological effects of occupational exposures to vibration by means of vibration sense thresholds.

Hand-arm vibration syndrome is an occupational disease caused by longitudinal exposure to hand transmitted vibration. Neurological disturbances in the upper extremities, together with vascular disorders characterised by Raynaud's phenomenon, are important symptoms of the vibration syndrome. Fingertip vibration sense thresholds are sometimes used to evaluate the neuropathy. ${ }^{12}$ Vibration sense thresholds are also useful for estimating acute physiological effects of hand-arm vibration exposures on the sensory system and investigating a permissible limit for occupational exposure to vibration. Several studies have related the temporary threshold shift (TTS) in vibration sense to the severity of vibration exposure..$^{3-6}$

The mechanoreceptors in the hand that play a part in the perception of vibration have not yet been completely confirmed anatomically. Verrillo et al have used psychophysical methods to demonstrate the presence of multiple mechanoreceptors that have different characteristics. ${ }^{78}$ Vallbo and Johansson studied characteristics of these mechanoreceptors with electrophysiological methods and divided the receptors into four types. ${ }^{9}$

Fast adapting (FA) units include Meissner corpuscles (FAI) that are sensitive at frequencies between $5 \mathrm{~Hz}$ and $50 \mathrm{~Hz}$. Another type of FA unit (FAII) is related to the Pacinian corpuscle (and possibly Golgi-Mazzoni bodies). The FAII units are sensitive at frequencies above 40 or $50 \mathrm{~Hz}$. Slowly adapting (SA) units include Merkel discs (SAI) and Ruffini endings (SAII) that are sensitive below eight or $16 \mathrm{~Hz}^{9-12}$ The frequency characteristics of the FAI and FAII units are influenced by conditions of measurement such as contact area, contact force, and surround. . $^{13-15}$

These studies were performed for physiological interest. Our study was carried out in the context of 
industrial health. The vibrating plate (contactor) for measuring vibration sense threshold imitated the vibration sensation meter widely used in Japan. ${ }^{16}{ }^{17}$ In our experiments of TTS induced by exposure to vibration, the vibration was applied by a handle to the subject's hand rather than to the narrow area of the hand where the vibration sense threshold was determined. A wide range of frequencies was used for both the vibration sense thresholds and the exposures to vibration.

The principal frequency range of the vibration sense thresholds investigated in this study was $16 \mathrm{~Hz}$ to $500 \mathrm{~Hz}$, which is considered to cover the response of the FAI and FAII units but not the SAI and SAII units. The predominant frequencies of most vibrating tools are in the range $16 \mathrm{~Hz}$ to $500 \mathrm{~Hz}$. Significant threshold changes in the vibration sense of the fingertips had previously been found at $63 \mathrm{~Hz}$, $125 \mathrm{~Hz}$, and $250 \mathrm{~Hz}$ in tool operators. ${ }^{16}$ Results of vibration sense threshold, step, and gap detection tests suggest that a threshold change in the FAII units is seen in users of vibration tools earlier than in the FAI units or the SAI units. ${ }^{18-20}$

Our study was composed of five experiments to determine: (1) frequency dependence of vibration sense thresholds, (2) effect of surround on thresholds, (3) effect of contact force on thresholds, (4) effect of temperature of finger skin on thresholds, and (5) characteristics of TTS induced by a provocative exposure to vibration.

\section{Subjects and methods}

Five subjects aged 23 to 28 were examined. All were healthy male research workers at the University of Southampton. The mean and standard deviation (SD) of body height were $180 \cdot 2, \mathrm{SD} 4.0 \mathrm{~cm}$ and body weight $72 \cdot 5$, SD $10.0 \mathrm{~kg}$.

All vibration sense thresholds were measured on the middle fingertip of the left hand. For measuring vibration sense thresholds a small shaker from the vibratory sensation meter (AU-02, RION), a power oscillator (TPO25, Ling Dynamic Systems), and a charge amplifier ( $5001 \mathrm{Sn}, \mathrm{KIAG}$ ) were used. The diameter of the circular plastic contactor used to determine vibrotactile thresholds was $7 \mathrm{~mm}$ with an area of $0.385 \mathrm{~cm}^{2}$. Three kinds of secured plastic plates with holes of different size acted as surrounds to the contactor (fig 1); two had holes with diameters of $10 \mathrm{~mm}$ (gap between the contactor and the surround $1.5 \mathrm{~mm}$ ) and $13 \mathrm{~mm}$ (gap $3 \mathrm{~mm}$ ), and the other had a rectangular hole of $26 \mathrm{~mm} \times 56 \mathrm{~mm}$ (no surround). The contact force applied to the vibrating plate by the fingertip was controlled at $1 \mathrm{~N}, 2 \mathrm{~N}$, or $3 \mathrm{~N}$. Figure 2 shows the controlling mechanism for contact force.

For vibration exposure to the hand in the TTS test, a vibrator (VP-85, Derritron Electronics) was
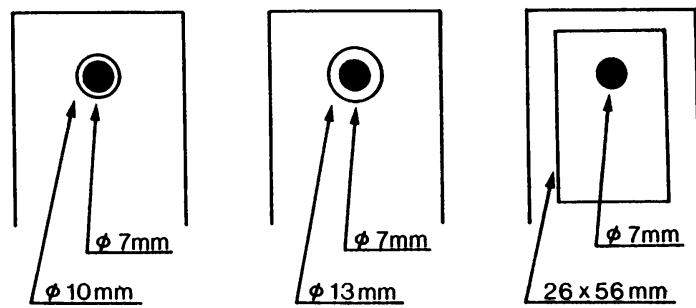

Figure 1 Size of surround. Diameter of contactor $7 \mathrm{~mm}$. Hole size of secured plastic plate either $10 \mathrm{~mm}$ diameter ( $1.5 \mathrm{~mm}$ gap), $13 \mathrm{~mm}$ diameter ( $3 \mathrm{~mm} \mathrm{gap}$ ), or $26 \times 56 \mathrm{~mm}$ (no surround).

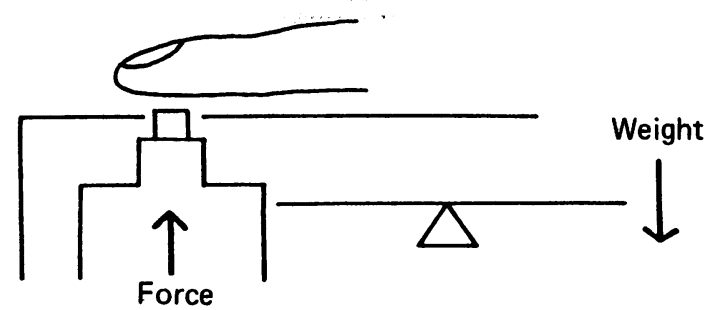

Figure 2 Apparatus to control contact force. Weights used were $100 \mathrm{~g}(1 \mathrm{~N}), 200 \mathrm{~g}(2 \mathrm{~N})$, and $300 \mathrm{~g}(3 \mathrm{~N})$. A ball bearing mechanism was adapted for the fulcrum.

used, and the handle temperature was controlied with a control master (RTL621, Raytel). The left hand was exposed to vibration for five minutes while grasping the handle with $10 \%$ of maximum grip force. The push and pull forces were controlled at zero. The temperature of the handle was thermostatically controlled at $30^{\circ} \mathrm{C}$ and the acceleration of the applied vibration was maintained at $20 \mathrm{~ms}^{-2} \mathrm{rms}$. The frequencies of the applied vibration were from $16 \mathrm{~Hz}$ to $500 \mathrm{~Hz}$ at octave band intervals. A control trial, in which subjects grasped the handle but were not exposed to vibration was also performed. After each exposure, three of the six frequencies $(16,31.5$, $63,125,250$, and $500 \mathrm{~Hz}$ ) of vibration sense threshold were measured. Two trials were therefore required for each frequency of vibration exposure and the control exposure. The sequence of exposures for each subject was determined at random.

Vibration sense thresholds were measured twice before exposure and then immediately, 0.5 minutes, two minutes, five minutes, 10 minutes, and 20 minutes after exposure. The intervals from exposure to measurement, however, varied with trials because three thresholds of different frequencies were measured in one trial of exposure. Therefore, TTS at 0.5 minutes after exposure $\left(\mathrm{TTS}_{0.5}\right)$ was calculated assuming proportional recovery of TTS with the logarithm of time after exposure, and using the measured vibration sense thresholds and the time intervals. $^{34}$ 
Vibration sense thresholds from $16 \mathrm{~Hz}$ to $500 \mathrm{~Hz}$ were measured at octave band intervals, except during experiment 1 in which those from $16 \mathrm{~Hz}$ to $800 \mathrm{~Hz}$ were measured at one third octave band intervals. The surround with a gap of $1.5 \mathrm{~mm}$ (size of hole $10 \mathrm{~mm}$ ) and a contact force of $2 \mathrm{~N}$ were used except in experiments 2 and 3. The atmospheric temperature of the laboratory was maintained at about $25^{\circ} \mathrm{C}$ except in experiment 4 when it was varied between $4^{\circ} \mathrm{C}$ and $29^{\circ} \mathrm{C}$. During experiments 4 and 5 , temperature of the skin on the dorsal side of the middle finger was measured with a digital thermometer (STK610, RS Components) just before measurement of the vibration sense threshold. The noise level during the experiments was $43-45 \mathrm{~dB}(\mathrm{~A})$, except in experiment 5 where it was 58-69 dB(A) (it rose to $81 \mathrm{~dB}(\mathrm{~A})$ during exposure to vibration at $500 \mathrm{~Hz}$ in experiment 5). During the measurement of the vibration sense thresholds before and after exposure, the noise level was 53-54 dB(A). Earmuffs (type 2315, Bilsom International) worn by subjects during the experiment may have decreased exposure to noise by $10 \mathrm{~dB}$ at $125 \mathrm{~Hz}$ and $25 \mathrm{~dB}$ at $500 \mathrm{~Hz}$.

Statistical tests were by multivariate analysis of variance and each objective factor was tested when taking subject variation into account.

\section{Results}

EXPERIMENT 1: FREQUENCY DEPENDENCE OF VIBRATION SENSE THRESHOLDS

Vibration sense thresholds of the fingertip were measured from $16 \mathrm{~Hz}$ to $800 \mathrm{~Hz}$ at one third octave band intervals while the finger skin temperature was kept at around $35^{\circ} \mathrm{C}$. The surround with a gap of $1.5 \mathrm{~mm}$ and contact force of $2 \mathrm{~N}$ were used. The threshold curve had one inflection point at $63-80 \mathrm{~Hz}$ (fig 3). The lowest threshold was nearly $0.03 \mathrm{~ms}^{-2}$ rms at $16 \mathrm{~Hz}$ and the highest was about $10 \mathrm{~ms}^{-2} \mathrm{rms}$ at $800 \mathrm{~Hz}$.

\section{EXPERIMENT 2: EFFECT OF SURROUND}

Figure 4 shows the effect of the surround and the gap to the contactor on thresholds. When not using the surround, the vibration sense threshold increased significantly by about $15-20 \mathrm{~dB}$ at $16 \mathrm{~Hz}$ and $31.5 \mathrm{~Hz}$, whereas it decreased by $2-5 \mathrm{~dB}$ at $125 \mathrm{~Hz}$, $250 \mathrm{~Hz}$, and $500 \mathrm{~Hz}$. Furthermore, the change induced by the smaller gap was larger than that induced by the larger gap at $16 \mathrm{~Hz}$ and $31.5 \mathrm{~Hz}$. The vibration sense threshold at $63 \mathrm{~Hz}$ showed no change. The effects of surround were statistically significant $(p<0.01)$ except at $63 \mathrm{~Hz}$ and $500 \mathrm{~Hz}$. The significance level at $500 \mathrm{~Hz}$ was $\mathrm{p}=0.057$.

\section{EXPERIMENT 3: EFFECT OF CONTACT FORCE}

Figure 5 compares vibration sense thresholds for three contact forces $(1 \mathrm{~N}, 2 \mathrm{~N}$, and $3 \mathrm{~N})$. An effect of

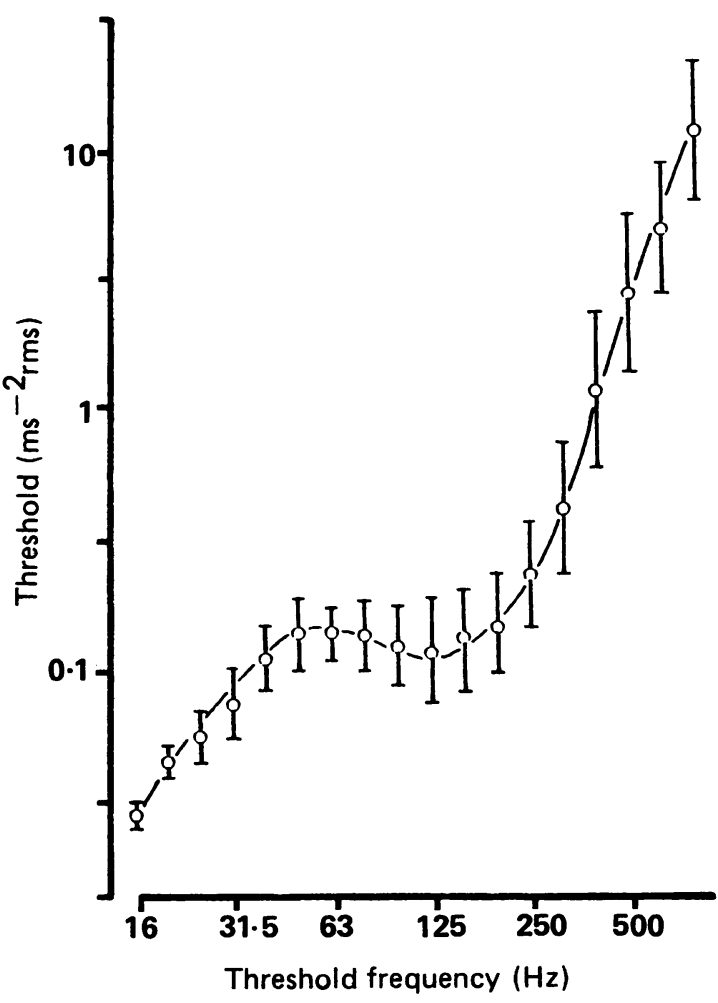

Figure 3 Frequency dependence of vibration sense thresholds of the fingertip. Surround with $1.5 \mathrm{~mm} \mathrm{gap}$, and contact force $2 N$ were used. Mean (SD) for five subjects are shown.

contact force was seen only at the higher frequencies; larger contact force led to lower thresholds at $125 \mathrm{~Hz}$, $250 \mathrm{~Hz}$, and $500 \mathrm{~Hz}$. The differences between the contact forces of $1 \mathrm{~N}$ and $3 \mathrm{~N}$ varied between $2 \mathrm{~dB}$ and $6 \mathrm{~dB}$. The effects of contact force were statistically significant at $125 \mathrm{~Hz}(\mathrm{p}<0.05), 250 \mathrm{~Hz}(\mathrm{p}<0.01)$, and $500 \mathrm{~Hz}(\mathrm{p}<0.05)$.

EXPERIMENT 4: EFFECT OF TEMPERATURE OF FINGER SKIN

Figure 6 shows the relation between vibration sense threshold and temperature of finger skin. The vibration sense threshold increased with decreasing temperature of finger skin; the changes at higher frequencies, such as $125 \mathrm{~Hz}, 250 \mathrm{~Hz}$, and $500 \mathrm{~Hz}$, were larger than those at lower frequencies. The difference of vibration sense threshold between $15^{\circ} \mathrm{C}$ and $35^{\circ} \mathrm{C}$ was around $10 \mathrm{~dB}$ at $125 \mathrm{~Hz}$ and $20 \mathrm{~dB}$ at $500 \mathrm{~Hz}$. The effects of skin temperature were statistically significant $(p<0.01)$ except at $63 \mathrm{~Hz}$.

EXPERIMENT 5: TTS $_{0.5}$ INDUCED BY EXPOSURE TO VIBRATION

Table 1 shows the change in temperature of finger 




Figure 4 Effect of surround on vibration sense thresholds of fingertip. Contact force $2 N$. Mean values for five subjects are shown.

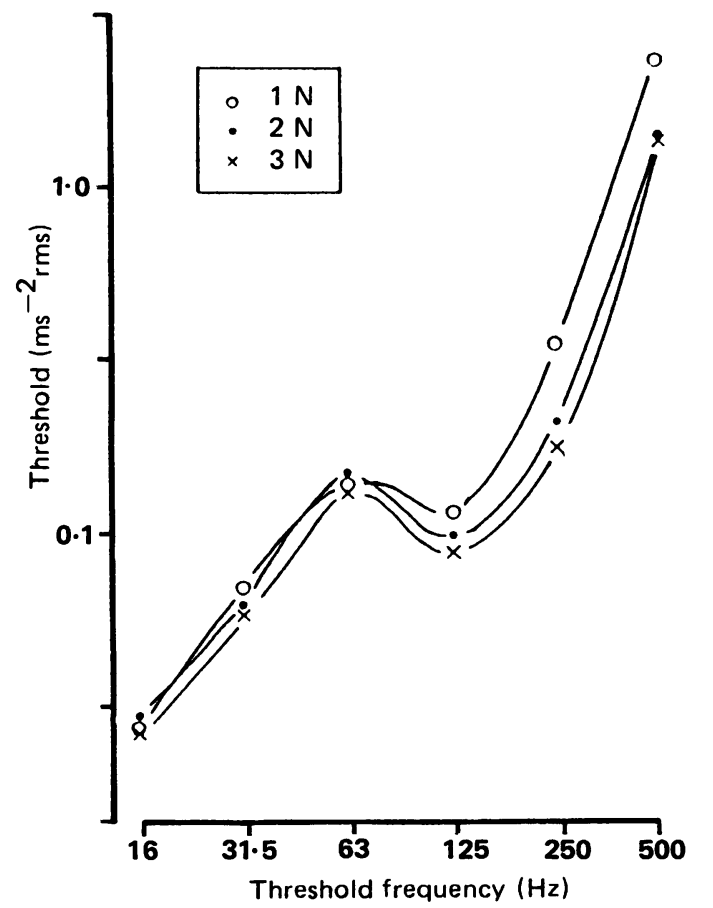

Figure 5 Effect of contact force on vibration sense thresholds of the fingertip. Surround with $1.5 \mathrm{~mm}$ gap was used. Mean values for five subjects are shown.

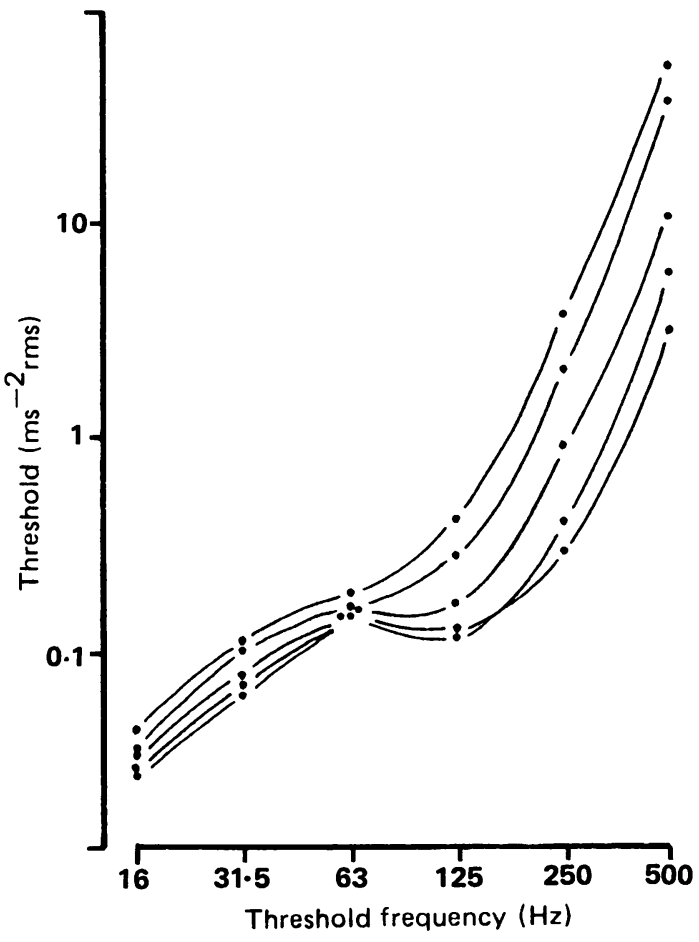

Figure 6 Effect of skin temperature on vibration sense thresholds of the fingertip. Black dot indicates vibration sense thresholds at skin temperature of $15 \pm 0.5^{\circ} \mathrm{C}, 20 \pm 0.5^{\circ} \mathrm{C}$, $25 \pm 0.5^{\circ} \mathrm{C}, 30 \pm 0.5^{\circ} \mathrm{C}$, and $35 \pm 0.5^{\circ} \mathrm{C}$ from top to bottom. Surround with gap of $1.5 \mathrm{~mm}$, and contact force $2 \mathrm{~N}$ were used. Mean values of five subjects are shown.

skin induced by exposure to vibration at $20 \mathrm{~ms}^{-2} \mathrm{rms}$ for five minutes. Exposure to vibration of $16 \mathrm{~Hz}$ and $500 \mathrm{~Hz}$ tended to induce greater decreases in temperature of finger skin. Although the decreases were small and not statistically significant compared with values before vibration exposure, the differences between exposure frequencies were statistically significant $(\mathrm{p}<0.05)$.

Figure 7 shows the TTS $_{0.5}$ of vibration sense induced by the exposure to vibration. Compared with the controls, in which subjects grasped the handle but were not exposed to vibration, the exposure to vibration at each frequency induced a significant increase in the vibration sense threshold. The TTS $_{0.5}$ of vibration sense at $16 \mathrm{~Hz}$ and $31.5 \mathrm{~Hz}$ was highest after exposure to lower frequencies of vibration, such as $16 \mathrm{~Hz}$ and $31.5 \mathrm{~Hz}$. The TTS $_{0.5}$ of vibration sense at $63 \mathrm{~Hz}$ was almost the same after exposures to all frequencies. The $\mathrm{TTS}_{0.5}$ of vibration sense at higher frequencies such as $125 \mathrm{~Hz}, 250 \mathrm{~Hz}$, and $500 \mathrm{~Hz}$ were highest after vibration exposure of $125 \mathrm{~Hz}$ and $250 \mathrm{~Hz}$. The differences in $\mathrm{TTS}_{0.5}$ of vibration sense between the six exposure frequencies (except controls) were statistically significant 
Table 1 Change of finger skin temperature induced by vibration exposure of $20 \mathrm{~ms}^{-2} \mathrm{rms}$ to the hand for five minutes: two trials of individual exposure conditions for each of five subjects

\begin{tabular}{|c|c|c|c|c|c|c|c|}
\hline \multirow{2}{*}{$\begin{array}{l}\text { Finger skin } \\
\text { temperature (mean } C(S D))\end{array}$} & \multirow[b]{2}{*}{ Control ${ }^{\star}$} & \multicolumn{6}{|c|}{ Frequency of exposed vibration } \\
\hline & & $16 \mathrm{~Hz}$ & $31.5 \mathrm{~Hz}$ & $63 \mathrm{~Hz}$ & $125 \mathrm{~Hz}$ & $250 \mathrm{~Hz}$ & $500 \mathrm{~Hz}$ \\
\hline $\begin{array}{l}\text { Before exposure } \\
\text { Immediately after exposure } \\
\text { Change }\end{array}$ & $\begin{array}{r}34.7(0.8) \\
33.3(1.2) \\
-1.3(1.1)\end{array}$ & $\begin{array}{r}34.7(0.9) \\
33.1(1.2) \\
-1.7(0.7)\end{array}$ & $\begin{array}{r}34.7(1.0) \\
33.7(0.8) \\
-1.0(0 \cdot 6)\end{array}$ & $\begin{array}{r}34.8(0.6) \\
33.4(0.6) \\
-1.4(0.8)\end{array}$ & $\begin{array}{r}34 \cdot 6(1 \cdot 0) \\
33 \cdot 4(1 \cdot 1) \\
-1 \cdot 2(0 \cdot 7)\end{array}$ & $\begin{array}{r}34.5(1.7) \\
33.3(1.5) \\
-1.1(0.7)\end{array}$ & $\begin{array}{r}35.1(0.5) \\
33.4(0.9) \\
-1.7(0.5)\end{array}$ \\
\hline
\end{tabular}

Differences of change in temperature among exposure frequencies statistically significant $(p<0.05)$.

${ }^{\star}$ Grasping a handle without exposure to vibration.

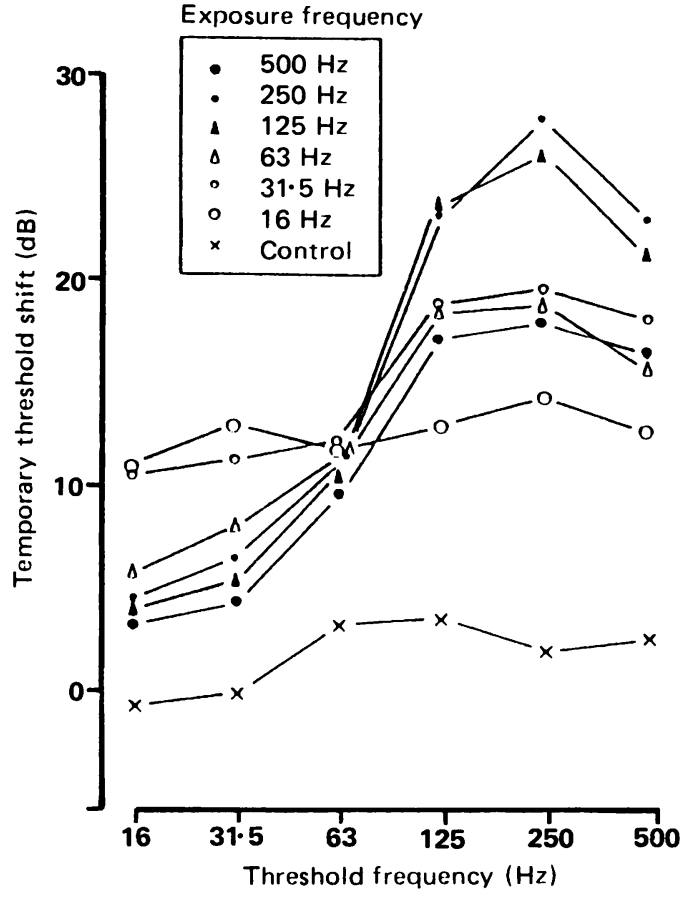

Figure $7 T T S_{0.5}$ of the vibration sense of the fingertip induced by exposure of the hand to vibration of $20 \mathrm{~ms}^{-2} \mathrm{rms}$. Surround with gap of $1.5 \mathrm{~mm}$, and contact force $2 \mathrm{~N}$ were used. Mean values of $T T S_{0.5}$ of five subjects are shown.

$(p<0.01)$ for each threshold frequency except $63 \mathrm{~Hz}$.

Figure 8 gives another representation of the results


function of exposure frequency for each threshold test frequency. The TTS $_{0.5}$ of the vibration sense at the higher test frequencies, such as $125 \mathrm{~Hz}, 250 \mathrm{~Hz}$, and $500 \mathrm{~Hz}$, were apparently different from those at lower frequencies such as $16 \mathrm{~Hz}$ and $31.5 \mathrm{~Hz}$. The effect on the TTS $_{0.5}$ at $63 \mathrm{~Hz}$ was between the effects at higher and lower frequencies.

\section{Discussion}

The vibration sense threshold curve shown in fig 3

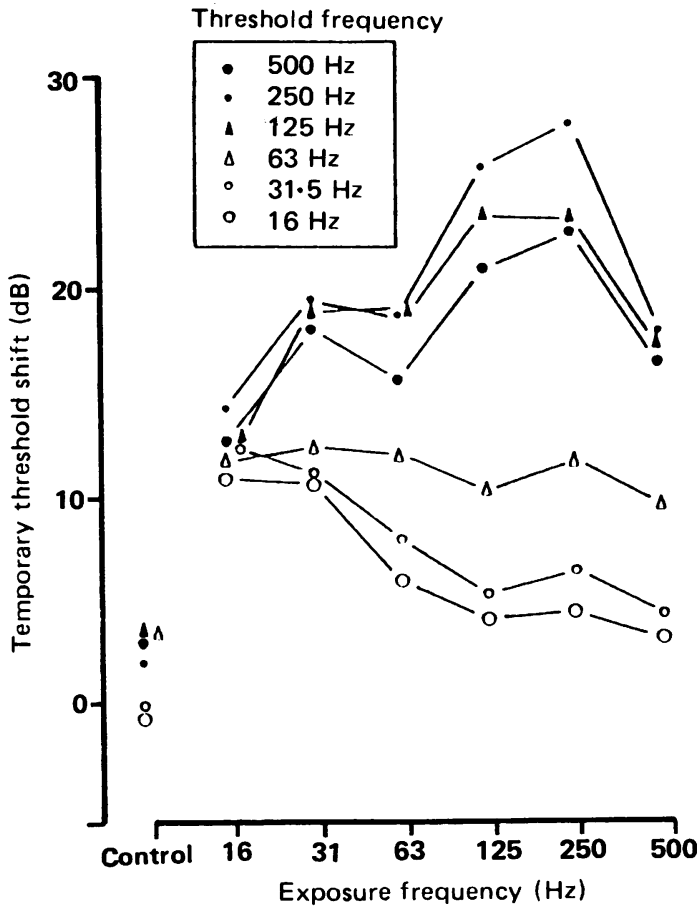

Figure $8 T T S_{0.5}$ of the vibration sense threshold of the fingertip (same data as fig 7).

consists of two parabolas with an inflection point at $63-80 \mathrm{~Hz}$. The contact area of $0.385 \mathrm{~cm}^{2}$ and the surround with a gap of $1.5 \mathrm{~mm}$ were used in this experiment. This threshold curve is very similar to that reported by Hayward. ${ }^{21} \mathrm{He}$ used a contactor of $0.283 \mathrm{~cm}^{2}$ and a rigid surround with a gap of $2 \mathrm{~mm}$. From Verrillo's results, the dominant mechanoreceptors under these measurement conditions are the FAI units below $60-80 \mathrm{~Hz}$ and the FAII units above this range. ${ }^{15}$ Therefore, the thresholds at $16 \mathrm{~Hz}$ and $31.5 \mathrm{~Hz}$ are thought to reflect the function of the FAI units and those at $125 \mathrm{~Hz}, 250 \mathrm{~Hz}$, and $500 \mathrm{~Hz}$ the FAII units.

Gesheider et $a l^{14}$ indicated that removal of the surround resulted in a decrease of $5.0 \mathrm{~dB}$ at $250 \mathrm{~Hz}$ and an increase of $16 \mathrm{~dB}$ at $10 \mathrm{~Hz}$ when measured on 
the thenar eminence using a contact area of $0.75 \mathrm{~cm}^{2}$. The magnitude of the change of threshold was similar in our results-namely, a decrease of $3.0 \mathrm{~dB}$ at $250 \mathrm{~Hz}$ and an increase of $19 \mathrm{~dB}$ at $16 \mathrm{~Hz}$. Furthermore, they showed that thresholds measured at $25 \mathrm{~Hz}$ increased by $3.0 \mathrm{~dB}$ for a doubling of the gap distance. ${ }^{22}$ This coincides with our results, which show increases of $3.0 \mathrm{~dB}$ at $16 \mathrm{~Hz}$ and $2.0 \mathrm{~dB}$ at $31.5 \mathrm{~Hz}$ by doubling the gap distance. The mechanism of these effects is thought to be because the FAII units have the capability of spatial summation causing a decrease in the threshold when not using the surround, whereas the FAI units do not have such a capability. On the other hand, the FAI units have a high sensitivity to abrupt discontinuities in stimulation provoked by the surround and so the threshold increases greatly when not using the surround. ${ }^{81423}$ Moore and Mundie ${ }^{24}$ investigated changes in mechanical characteristics induced by the presence of a surround and concluded that such changes were confirmed in the forearm and the thenar eminence but not in the finger.

Craig and Sherrick ${ }^{25}$ found that doubling the contact force increased the magnitude of vibration sense by around $3 \mathrm{~dB}$ when using a contact area of $0.157 \mathrm{~cm}^{2}$ and a contact force varying from 0.025 to $0.8 \mathrm{~N}$ on the forearm, an area thought not to have FAI units. ${ }^{26}$ Ohkouchi indicated that the vibration sense threshold of the fingertip at $250 \mathrm{~Hz}$ was not changed with contact forces over $2 \mathrm{~N}^{27}$ These findings are consistent with the results in this study. Vibration sense thresholds decreased by 1 to $5 \mathrm{~dB}$ at $125 \mathrm{~Hz}, 250 \mathrm{~Hz}$, and $500 \mathrm{~Hz}$ when the contact force was increased from $1 \mathrm{~N}$ to $2 \mathrm{~N}$ whereas no difference in vibration sense threshold was seen between $2 \mathrm{~N}$ and $3 \mathrm{~N}$. The effect of contact force might be explained by spatial summation in the FAII units.

Green $^{28}$ investigated the effect of skin temperature on vibration sense thresholds using a narrow contact area of $0.008 \mathrm{~cm}^{2}$ without a surround and showed that a decrease in skin temperature from $37^{\circ} \mathrm{C}$ to $20^{\circ} \mathrm{C}$ induced an increase in the vibration sense threshold of $6 \mathrm{~dB}$ at $150 \mathrm{~Hz}$ and $16 \mathrm{~dB}$ at $250 \mathrm{~Hz}$. Such an effect of temperature was not seen, however, at $80 \mathrm{~Hz}$ and the lower frequencies. He concluded that Pacinian corpuscles are sensitive to temperature changes but low frequency receptors are not. Although our measuring conditions differed from his in contact area and the presence of surround, the results were similar; a decrease in skin temperature from $35^{\circ} \mathrm{C}$ to $20^{\circ} \mathrm{C}$ induced an increase in vibration sense threshold of $6 \mathrm{~dB}$ at $125 \mathrm{~Hz}$ and $16 \mathrm{~dB}$ at $250 \mathrm{~Hz}$. This effect of temperature was also seen, however, at the lower frequencies of $16 \mathrm{~Hz}$ and $31.5 \mathrm{~Hz}$. Although it is likely that lower temperatures induced lower function of neurological systems including the FAI units, it is apparent that the FAII units are much more sensitive to changes in temperature than the FAI units.
In the TTS experiment, exposure to vibration did not induce significant decreases in skin temperature. This may be due to the constant handle temperature of $30^{\circ} \mathrm{C}$. A significant decrease in the temperature of finger skin in this experiment would have confounded the results and it was necessary to eliminate the effect of temperature change on the TTS of vibration sense, which is easily influenced by skin temperature as shown in experiment 4.

Verrillo and Gescheider ${ }^{29}$ and Gescheider et $a l^{14}$ indicated that exposure to vibration at $10 \mathrm{~Hz}$ and $250 \mathrm{~Hz}$ induced significant TTS of vibration sense, at lower frequencies relating to the FAI units and at higher frequencies to the FAII units. An experiment reported by Lundström and Johansson ${ }^{10}$ confirmed these results using an electrophysiological method. Our results are similar with one exception; exposure to vibration at lower frequencies also induced small but significant TTS of vibration sense at higher frequencies. Our study and the physiological studies mentioned above differ in their methods of exposure to vibration. They used the same contactor to measure vibration sense threshold and to apply vibration to the skin, whereas we used a handle to apply vibration to the whole hand. It is possible that the combined effects of grasping a handle and exposure to vibration induced ischaemia in the tissues, then hypofunction of both FAI and FAII units. The finding that grasping without exposure to vibration induced a small TTS at the higher frequencies of vibration sense supports this speculation.

Harada $^{45}$ used a large plate to expose the hand to vibration and measured TTS of vibration sense at $63 \mathrm{~Hz}, 125 \mathrm{~Hz}$, and $250 \mathrm{~Hz}$. Nishiyama et al ${ }^{6}$ used a handle and investigated TTS of vibration sense at $125 \mathrm{~Hz}$ with various conditions of exposure. Although in the above studies the vibration sense thresholds measured were limited to a few frequencies, the TTS levels were similar to those in the present study. Bjerker et $a l^{3}$ investigated TTS of vibration sense from $50 \mathrm{~Hz}$ to $800 \mathrm{~Hz}$ induced by exposure of the hand to vibration from $50 \mathrm{~Hz}$ to $800 \mathrm{~Hz}$. Their results differed from ours, possibly because the interval between exposure to vibration and threshold measurement was different among the frequencies studied.

In the TTS experiment, two important observations were made. One was that the TTS differed appreciably above and below $63 \mathrm{~Hz}$. The other was that the frequency dependence of TTS to exposure vibration was similar within the two groups of frequencies (for 16 and $31.5 \mathrm{~Hz}$ and for 125,250 , and $500 \mathrm{~Hz}$; see fig 8). The frequency showing the largest TTS was the same within each group. The lower exposure vibration frequencies of $16 \mathrm{~Hz}$ and $31.5 \mathrm{~Hz}$ induced the largest TTS at test frequencies of $16 \mathrm{~Hz}$ and $31.5 \mathrm{~Hz}$. The upper exposure frequencies of $125 \mathrm{~Hz}$ and $250 \mathrm{~Hz}$ induced the highest TTS at 
$125 \mathrm{~Hz}, 250 \mathrm{~Hz}$, and $500 \mathrm{~Hz}$. The test frequency of $63 \mathrm{~Hz}$ had intermediate values between upper and lower frequencies. These data indicate that maximal TTS may be induced in the FAI and FAII units by exposure to vibration of different frequencies. This may be an important finding when assessing effects of vibration using the TTS of vibration sense in an industrial area. The results suggest that two representative test frequencies can be used for TTS measurements of the FAI and FAII units in experimental and field studies, and possibly for the diagnosis of the neurological damage in patients with hand-arm vibration syndrome.

\section{Conclusion}

Table 2 summarises the results of this study. When measuring vibration sense thresholds, frequencies under $63 \mathrm{~Hz}$ are considered to reflect the FAI units and over $63 \mathrm{~Hz}$ the FAII units. The physiological characteristics of the vibration sense of low and high frequencies differ clearly from one another. Some of the findings are consistent with earlier studies, but two inconsistent findings were obtained. Temperature had an observable effect on vibration sense thresholds at frequencies below $63 \mathrm{~Hz}$, relating to the FAI units. Exposure to vibration at low frequencies (below $63 \mathrm{~Hz}$ ) induced significant TTS of vibration sense at high frequencies (above $63 \mathrm{~Hz}$ ). The mechanism of this effect may be the combined contribution of grasping the handle and exposure to vibration. The dependence of vibration sense thresholds on the surround, contact force, skin temperature, and previous exposure to vibration may be important when evaluating the effects of exposure to vibration on the hand-arm system using vibration sensation.

This study was performed at the Human Factors Research Unit, Institute of Sound and Vibration Research, Southampton University, England. The authors thank all the members for their collaboration and useful discussions.

Requests for reprints to: Dr Noriaki Harada, Department of Hygiene, Yamaguchi University School of Medicine, Ube, Yamaguchi 755, Japan.
1 Hayward RA, Griffin MJ. Measures of vibrotactile sensitivity in persons exposed to hand-arm vibration. Scand JWork Environ Health 1986;12:423-7.

2 Harada N. Esthesiometry, nail compression and other function tests used in Japan for evaluating the hand-arm vibration syndrome. Scand J Work Environ Health 1987;13:330-3.

3 Bierker N, Kylin B, Lidström IM. Changes in the vibratory sensation threshold after exposure to powerful vibration. Ergonomics 1972;15:399-406.

4 Harada N. Studies on the changes in the vibratory sensation threshold at the fingertip in relation to some physical parameters of exposed vibration. Part 1. A study on the methods of vibration exposure and measurement of the vibratory sensation threshold. Japanese Journal of Hygiene 1978;33:699-705. (In Japanese with English abstract.)

5 Harada N. Studies on the changes in the vibratory sensation threshold at the fingertip in relation to some physical parameters of exposed vibration. Part 2. A study on the equal TTS curves of the vibratory sensation and hygienic allowable limit of portable mechanized tool. Japanese Journal of Hygiene 1978;33:706-17. (In Japanese with English abstract.)

6 Nishiyama K, Watanabe S. Temporary threshold shift of vibratory sensation after clasping a vibrating handle. Int Arch Occup Environ Health 1981;49:21-33.

7 Verrillo RT. A duplex mechanism of mechanoreception. In: Kenshalo DR, ed. The skin senses. Springfield IL: Thomas, 1966:139-59.

8 Verrillo RT. Psychophysics of vibrotactile stimulation. J Acoust Soc Am 1985;77:225-32.

9 Vallbo AB, Johansson RS. Properties of cutaneous mechanoreceptors in the human hand related to touch sensation. Human Neurobiology 1984;3:3-14.

10 Lundström R, Johansson RS. Acute impairment of the sensitivity of skin mechanoreceptive units caused by vibration exposure of the hand. Ergonomics 1986;29:687-98.

11 Johansson RS, Landström U, Lundström R. Responses of mechanoreceptive afferent units in the glabrous skin of the human hand to sinusoidal skin displacements. Brain Res 1982;244:17-25.

12 Johansson RS. Tactile sensibility in the human hand: Receptive field characteristics of mechanoreceptive units in the glabrous skin area. $J$ Physiol (Lond) 1978;281:101-23.

13 Verrillo RT, Capraro AJ. Effect of stimulus frequency on subjective vibrotactile magnitude functions. Perception and Psychophysics 1975;17:91-6.

14 Gescheider GA, Frisina RD, Verrillo RT. Selective adaptation of vibrotactile thresholds. Sensory Processes 1979;3:37-48.

15 Verrillo RT. Effect of contactor area on the vibrotactile threshold. J Acoust Soc Am 1963;35:1962-6.

16 Harada N, Yamada S, Matsumoto T. Changes of the vibratory sensation threshold in workers using vibrating tools. Jpn J Ind Health 1976;18:395-402. (In Japanese with English abstract.)

17 Harada N, Matsumoto T. Validity of various function tests performed in Japan as a screening test for vibration syndrome. Int Arch Occup Environ Health 1984;54:283-93.

18 Brammer AJ, Taylor W, Piercy JE. Assessing the severity of the neurological component of the hand-arm vibration syndrome. Scand J Work Environ Health 1986;12:428-31.

19 Brammer AJ, Piercy JE, Auger PL. Assessment of impaired tactile sensation. Scand J Work Environ Health 1987;13: $380-4$.

20 Brammer AJ, Piercy JE, Auger PL, Nohara S. Tactile perception in hands occupationally exposed to vibration. $J$ Hand Surg $(\mathrm{Br})$ 1987;12A:870-5.

21 Hayward RA. Vibrotactile thresholds: Reproducibility and frequency function. United Kingdom informal group meeting on

Table 2 Summary of effects of four factors on vibration sense thresholds

\begin{tabular}{|c|c|c|c|c|c|c|}
\hline & \multicolumn{6}{|c|}{ Threshold test frequency } \\
\hline & $16 \mathrm{~Hz}$ & $31.5 \mathrm{~Hz}$ & $63 \mathrm{~Hz}$ & $125 \mathrm{~Hz}$ & $250 \mathrm{~Hz}$ & $500 \mathrm{~Hz}$ \\
\hline Surround & $\downarrow \downarrow \downarrow$ & $\downarrow \downarrow \downarrow$ & - & $\uparrow$ & $\uparrow$ & $\uparrow$ \\
\hline $\begin{array}{l}\text { Contact pressure } \\
\text { Skin temperature }\end{array}$ & & & $\overline{1}$ & & & \\
\hline Largest TTS & $16 / 31.5 \mathrm{~Hz}$ & $16 / 31.5 \mathrm{~Hz}$ & $\stackrel{\downarrow}{-}$ & $125 / 250 \mathrm{~Hz}$ & $125 / 250 \mathrm{~Hz}$ & $125 / 250 \mathrm{~Hz}$ \\
\hline
\end{tabular}

$\uparrow$ Increase of threshold; - no change; $\downarrow$ decrease of threshold. 
human response to vibration. Loughborough University of Technology, 1986.

22 Verrillo RT. The effect of surface gradients on vibrotactile thresholds. Sensory Processes 1979;3:27-36.

23 Gescheider GA, Capraro AJ, Frisina RD, Hamer RD, Verrillo RT. The effects of a surround on vibrotactile thresholds. Sensory Processes 1978;2:99-115.

24 Moore TJ. Mundie JR. Measurement of specific mechanical impedance of the skin: Effects of static force, site of stimulation, area of probe, and presence of a surround. J Acoust Soc Am 1972;52:577-84.

25 Craig JC, Sherrick CE. The role of skin coupling in the determination of vibrotactile spatial summation. Perception and Psychophysics 1969;6:97-101.

26 Winkelmann RK. The Meissner corpuscle. In: Nerve endings in normal and pathologic skin. Springfield IL: Thomas, 1960: 58-70.

27 Ohkouchi $T$. On measurement of vibratory perception ability and its clinical application. Rinshosinkei 1972;12:413-22. (In Japanese with English abstract.)

28 Green BG. The effect of skin temperature on vibrotactile sensitivity. Perception and Psychophysics 1977;21:243-8.

29 Verrillo RT, Gescheider GA. Effect of prior stimulation on vibrotactile thresholds. Sensory Processes 1977;1:292-300.

Accepted 2 July 1990

\section{Destruction of manuscripts}

From 1 July 1985 articles submitted for publication will not be returned. Authors whose papers are rejected will be advised of the decision and the manuscripts will be kept under security for three months to deal with any inquiries and then destroyed. 